\title{
Corticosterone suppresses IL-1 $\beta$-induced mPGE2 expression through regulation of the 11/-HSD1 bioactivity of synovial fibroblasts in vitro
}

\author{
BO WEI ${ }^{1}$, ZHAOBO ZHU $^{1}$, MIN XIANG ${ }^{1}$, LIJUN SONG ${ }^{2}$, \\ WEIXIONG GUO ${ }^{1}$, HAO LIN ${ }^{1}$, GUANGSHENG LI ${ }^{1}$ and RONG ZENG ${ }^{1}$ \\ ${ }^{1}$ Orthopedic Centre; ${ }^{2}$ Reproductive Research Department, Affiliated Hospital of Guangdong Medical College, \\ Zhanjiang, Guangdong 524001, P.R. China
}

Received November 21, 2015; Accepted December 9, 2016

DOI: $10.3892 /$ etm.2017.4238

\begin{abstract}
The aim of the present study was to investigate the correlation between glucocorticoid activity regulation, prostaglandin $\mathrm{E} 2\left(\mathrm{PGE}_{2}\right)$ synthesis, and synovial inflammation inhibition activity, through microsomal prostaglandin $\mathrm{E}$ synthase-1 (mPGES-1) expression regulated by the glucocorticoid pre-receptor regulator, 11 $\beta$-hydroxysteroid dehydrogenase-1 (11 $\beta$-HSD1). In the present study, fibroblast-like synovial cells of rats were studied as a cell model. Cells were stimulated with $10 \mathrm{ng} / \mathrm{ml}$ interleukin (IL)- $1 \beta$ for $24 \mathrm{~h}$, and were subsequently, within the next $24 \mathrm{~h}$, treated with or without $10^{-6} \mathrm{mmol} / \mathrm{l}$ corticosterone alone or with $100 \mathrm{nmol} / 1$ PF915275. At the end of the second $24 \mathrm{~h}, \mathrm{PGE}_{2}$ levels in culture supernatants were assayed. Cells were harvested for mRNA evaluation of $11 \beta$-HSD1, mPGES-1, IL-1 $\beta$ and tumor necrosis factor (TNF)- $\alpha$, and protein detection of $11 \beta-H S D 1$ and mPGES-1 using reverse transcription-qualitative polymerase chain reaction and western blot analysis, respectively. Corticosterone was demonstrated to suppress the mRNA expression levels of inflammatory factors, such as TNF- $\alpha$ and $\mathrm{PGE}_{2}$, induced by IL-1 $\beta$ in vitro. Simultaneously, expression levels of $11 \beta$-HSD1 decreased significantly at the mRNA and protein levels $(\mathrm{P}<0.05)$. Cortisol concentration in the medium of the group treated with corticosterone was significantly increased $(\mathrm{P}<0.05)$ compared with that of the control group; however, the cortisol concentration was decreased in the medium when the conversion bioactivity of $11 \beta-H S D 1$ was inhibited by PF915275, while the changes in 11 $\beta$-HSD1 and mPGES- 1 mRNA expression levels and $\mathrm{PGE}_{2}$ content were reversed in
\end{abstract}

Correspondence to: Professor Bo Wei, Orthopedic Centre, Affiliated Hospital of Guangdong Medical College, 57 South Renmin Road, Xiashan, Zhanjiang, Guangdong 524001, P.R. China E-mail:webjxmc@163.com

Key words: corticosterone, 11ß-hydroxy steroid dehydrogenase-1, microsomal prostaglandin E synthase-1, prostaglandin E2, inflammation suppression the medium. These results indicated that a significant positive correlation $(\mathrm{P}<0.01)$ may exist between mRNA and protein expression levels. To conclude, $11 \beta-\mathrm{HSD} 1$ is a key regulator for the synthesis of mPGES-1 and $\mathrm{PGE}_{2}$ in the inflammatory synovial cells in vitro, suggesting a potential interference target for osteoarthritis.

\section{Introduction}

Osteoarthritis (OA) was once considered as a non-inflammatory form of arthritis, but studies have demonstrated that synovitis is associated with major symptoms of OA, such as pain and the degree of joint dysfunction, and may promote more rapid cartilage degeneration (1-3). Synovial inflammation is an important factor involved in the acceleration of cartilage degeneration $(4,5)$. It is likely that multiple joint tissues contribute to joint inflammation (6). Fibroblast-like cells (FLS) are the main functional synovial cells that produce cytokines, such as tumor necrosis factor (TNF)- $\alpha$, interleukin (IL)-1 $\beta$, IL-1 $\beta$ and IL-6, which are involved in the degradation of cartilage (7). FLS can also affect the natural course of arthritis by releasing prostaglandin $\mathrm{E} 2\left(\mathrm{PGE}_{2}\right)(8)$.

It is now known that several cell types are able to generate active glucocorticoids within their cytoplasm through expression of the 11 $\beta$-hydroxysteroid dehydrogenase type 1 (11/-HSD1) enzyme. The generation of active glucocorticoids in the synovium is strongly linked to the level of inflammation. Hardy et al (9) reported that 11 $\beta$-HSD1 mRNA was highly expressed in synovial tissues affected by OA, and its activity was increased, as indicated by IL- $1 \beta$ and TNF- $\alpha$. Synovial fibroblasts have been demonstrated to maintain the balance between intracellular glucocorticoid activation and inactivation, and execute biological effects by producing 11 $\beta$-HSD1 and binding with its receptor $(9,10)$. It has been reported that, in fetal membranes and adipose tissues, 11 $\beta$-HSD1 mRNA expression and protein levels are upregulated by pro-inflammatory cytokines $(11,12)$. Sun and Myatt reported a coordinated induction effect existed for the regulation of $11 \beta-H S D 1$ by glucocorticoids and pro-inflammatory cytokines (11). Glucocorticoids usually play an opposing role to proinflammatory cytokines at sites of inflammation $(13,14)$. However, how the 
glucocorticoid and pro-inflammatory mediators induce their effects on $11 \beta$-HSD1, or whether $11 \beta$-HSD1 correlates with $\mathrm{PGE}_{2}$ expression in the synovial fibroblasts, remains unclear.

Therefore, we hypothesized that glucocorticoid activity correlated with $\mathrm{PGE}_{2}$ synthesis, and that the glucocorticoid pre-receptor regulator, 11ß-HSD1, may have an effect on relieving synovial inflammation by inhibiting microsomal prostaglandin E synthase-1 (mPGES-1) and $\mathrm{PGE}_{2}$ expression. In the present study, a model cell, fibroblast-like synovial cell, derived from rats, was stimulated with IL-1 $\beta$ and the effect of treatment with corticosterone and 4'-cyano-biphenyl-4-sulfonic acid (6-amino-pyridin-2-yl)-amide was evaluated. $\mathrm{PGE}_{2}$ levels in culture supernatants were assayed, the mRNA expression of $11 \beta$-HSD1, mPGES-1, IL-1 $\beta$ and TNF- $\alpha$ by the cells was analyzed and reverse transcription-qualitative polymerase chain reaction and western blot analysis were used to detect protein expression of $11 \beta-H S D 1$ and mPGES-1. The anti-inflammatory mechanism of glucocorticoid in suppressing IL- $\beta$ induced mPGES-1 expression through regulation of 11 $\beta$-HSD1 bioactivity in synovial fibroblasts in vitro was explored.

\section{Materials and methods}

Isolation and culture of Sprague-Dawley (SD) rat synoviocytes. Synovial fibroblasts were isolated from the knee synovial tissue of 10 female healthy 3-month SD rats (200 \pm 30 g; Laboratory Animal Centre, Guangdong Medical College, Zhanjiang, China). Rats were kept under regular conditions with a temperature of $25^{\circ} \mathrm{C}$, humidity of $50 \%$ and a natural day and night cycle. All rats were able to access food and water freely. Rats were euthanatized with an intraperitoneal overdose $(130 \mathrm{mg} / \mathrm{kg})$ of phenobarbital sodium (cat. no. P5178; Sigma-Aldrich; Merck Millipore, Darmstadt, Germany) in accordance with National Animal Care guidelines. The protocol was approved by the Ethics Committee of Guangdong Medical College. Synovial tissues were cut into pieces $\left(2-3 \mathrm{~mm}^{2}\right)$ and subsequently immersed in Dulbecco's modified Eagle's medium (DMEM) supplemented with 15\% fetal bovine serum, $100 \mathrm{U} / \mathrm{ml}$ penicillin and $100 \mu \mathrm{g} / \mathrm{ml}$ streptomycin (all Gibco ${ }^{\mathrm{TM}}$; Thermo Fisher Scientific, Inc., Waltham, MA, USA). Tissue pieces were transferred into a culture flask, with 15-20 pieces in each bottle. Culture bottles were inverted and $2 \mathrm{ml}$ medium was added. Tissue pieces were cultured at $37^{\circ} \mathrm{C}$ in a humidified atmosphere, containing $5 \% \mathrm{CO}_{2}$ for 2-3 h. Culture bottles were reversed when tissue blocks adhered to the bottom. Medium was replenished every 2 days. Cells were separated from the synovial tissue and passaged when confluent. Synovial fibroblasts after three passages were analyzed using flow cytometry [for cluster of differentiation (CD) 90] and vimentin immunocytochemical staining.

Flow cytometric analysis. The passage 3 synovial cells were digested with $1 \mathrm{ml} 0.25 \%$ trypsin (cat. no. 25-200-114; Gibco; Thermo Fisher Scientific, Inc). FBS-DMEM medium $(10 \%, 3 \mathrm{ml})$ was added to terminate the digestion when the morphology of cell became rounded and the cells were removed from the bottle wall. The digested cell suspension was loaded into a $15-\mathrm{ml} \mathrm{EP}$ tube and centrifuged at 1,344 $\mathrm{x} g$ for $5 \mathrm{~min}$. The supernatant was removed and the cells were suspended and divided into two EP tubes (1.5 ml). One tube of cells was labeled with $5 \mu \mathrm{l}$ phycoerythrin (PE)-labeled anti-rat CD90 (cat. no. 205903; Biolegend Inc., San Diego, CA, USA). The other was labeled with the same host-derived IgG (cat. no. 400111; Biolegend Inc.) as a negative control. The cells were incubated at $4^{\circ} \mathrm{C}$ in the dark for $30 \mathrm{~min}$ and then centrifuged at $1,344 \times g$ for $5 \mathrm{~min}$. The supernatant was removed and resuspended with $500 \mu \mathrm{l}$ PBS. The cell populations were analyzed using a FACSCalibur Flow Cytometer (BD FACSCanto; BD Biosciences, San Jose, CA, USA).

Vimentin immunocytochemical staining. The cells were fixed with $4 \%$ formaldehyde for $30 \mathrm{~min}$. Then, the cells were washed in PBS for $5 \mathrm{~min}$, incubated in $3 \% \mathrm{H}_{2} \mathrm{O}_{2}$ and in $0.3 \%$ Triton $\mathrm{X}-100$ solution for $30 \mathrm{~min}$, respectively, and then blocked with BSA at room temperature for $10 \mathrm{~min}$. The cells were incubated with primary antibody vimentin mouse anti-rat antibody (1:300 dilution; cat. no. BM0135; Wuhan Boster Biological Technology, Ltd., Wuhan, China). Instead of primary antibody, PBS was added as a negative control. The cells were incubated at $4^{\circ} \mathrm{C}$ overnight. The next day, the slices were washed in PBS for 5 min, 3 times, and then incubated with secondary antibody (polymeric HRP-Conjugated Anti-Goat IgG Super Vision Assay kit; cat. no. SV0003-1; Wuhan Boster Biological Technology, Ltd.) at room temperature for $30 \mathrm{~min}$. DAB chromogen was used according to the manufacturer's guidance (Wuhan Boster Biological Technology, Ltd.).

Study design. Synovial fibroblasts, preserved in DMEM, were removed of glucocorticoid using $10 \%$ active carbon and subsequently stimulated with $10 \mathrm{ng} / \mathrm{ml}$ IL-1 $\beta$ (R\&D Systems, Inc., Minneapolis, MN, USA) for $24 \mathrm{~h}$. Synovial fibroblast cells were washed with PBS at $37^{\circ} \mathrm{C}$ for $5 \mathrm{~min}$, three times. After $24 \mathrm{~h}$, cells were treated with different components depending on the allocated group: Group A, treated with DMEM without

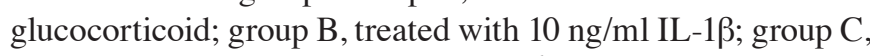
treated with $10 \mathrm{ng} / \mathrm{ml} \mathrm{IL}-1 \beta$ and $10^{-6} \mathrm{mmol} / 1$ corticosterone

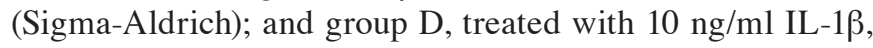
$10^{-6} \mathrm{mmol} / \mathrm{l}$ corticosterone and $100 \mathrm{nmol} / \mathrm{l} \mathrm{PF} 915275$ (Tocris Bioscience, Bristol, UK). Following a further $24 \mathrm{~h}, \mathrm{PGE}_{2}$ levels were assayed in culture supernatants by ELISA. Cells were harvested for mRNA evaluation of 11 $\beta$-HSD1, mPGES-1, IL-1 $\beta$ and TNF- $\alpha$ levels; and protein expression level detection of $11 \beta$-HSD1 and mPGES-1.

$R N A$ extraction and reverse transcription-quantitative real-time polymerase chain reaction ( $R T-q P C R)$ analysis. Total RNA was isolated from synovial fibroblast layers using TRIzol reagent (Takara Biotechnology Co., Ltd., Dalian, China) following the manufacturer's protocol. RNA quality was detected by agarose gel electrophoresis. Reverse transcription was carried out using the PrimeScript RT Reagent kit (Takara Biotechnology Co., Ltd.). The mRNA expression of IL-1 $\beta$, TNF- $\alpha, 11 \beta$-HSD1 and mPGES- 1 was determined using the SYBR Premix Ex Taq ${ }^{\mathrm{TM}}$ kit (Takara Biotechnology Co., Ltd.). The volume of the reaction system was $15 \mu \mathrm{l}$, and the reaction system contained 7.5 $\mu$ l SYBR Premix Ex Taq II, $0.6 \mu 1$ each upstream and downstream primer, $1.5 \mu \mathrm{l}$ DNA template and $4.8 \mu 1$ sterilized distilled water. Target mRNA levels were normalized to $\beta$-actin expression levels. Primers 
used in the experiment are listed below. The following cycling conditions were used: $95^{\circ} \mathrm{C}$ for $2 \mathrm{~min}$, followed by 40 cycles of $95^{\circ} \mathrm{C}$ for $15 \mathrm{sec}$ and $60^{\circ} \mathrm{C}$ for $30 \mathrm{sec}$. Three replications of this experiment were performed for the same reaction. A Real-time Quantitative PCR instrument (Bio-Rad Laboratories, Inc., Hercules, CA, USA) and the $2^{-\Delta \Delta C q}$ method (15) with LERTPA-V1.0 software (http://www.biostatistic.net/portal. php) was used to analyze the relative gene expression data: Experimental group $(\mathrm{Cq}$ target gene- $\mathrm{Cq}$ housekeeping gene)-blank group ( $\mathrm{Cq}$ target gene- $\mathrm{Cq}$ housekeeping gene). The $\mathrm{Cq}$ value in this formula represented the number of amplification cycles required for a fluorescent signal in each well to reach a specific threshold. The $\mathrm{Cq}$ value was automatically calculated by the computer based on the amplification curve. Gene-specific primer pairs used were as follows: IL-1 $\beta$, forward 5'-CTTCAAATCTCACAGCAGCATC-3' and reverse 5'-GCTGTCTAATGGGAACATCACA-3'; TNF- $\alpha$, forward 5'-GTGCCTCAGCCTCTTCTCATT-3' and reverse 5'-CTC TGCTTGGTGGTTTGCTAC-3'; 11 $\beta$-HSD1, forward 5'-AAA ATGACCCAGCCTATGATTG-3' and reverse 5'-GGACAC AGAGAGTGATGGACAC-3'; mPGES-1, forward 5'-GTG ATGGAGAACAGCCAGGT-3' and reverse 5'-CAAGGAAGA GGAAGGGGTAGAT-3'; and $\beta$-actin, forward 5'-CCATCT ATGAGGGTTACGC-3' and reverse 5'-TTTAATGTCACG CACGATTTC-3'.

Assays for $\mathrm{PGE}_{2}$ and cortisol. Levels of $\mathrm{PGE}_{2}$ in culture supernatants were determined using an ELISA kit (cat. no. KGE004B; R\&D Systems, Inc.) in accordance with the manufacturer's instructions. Assays were based on the combined use of a monoclonal antibody against $\mathrm{PGE}_{2}$ and an alkaline phosphatase-conjugated polyclonal antibody; $p$-nitrophenyl phosphate substrate was added, and the absorbance at $405 \mathrm{~nm}$ was analyzed using a micro Multiskan plate reader. The limits of detection were 10 and $1.4 \mathrm{pg} / \mathrm{ml}$ for $\mathrm{PGE}_{2}$. Positive controls were used in each experiment.

Cortisol levels were also determined in culture supernatants using an ELISA kit (cat. no. KGE008B; R\&D Systems, Inc.), in accordance with manufacturer's instructions to indicate the conversion rate of cortisone. The assay required microtiter plates coated with purified antibody and the standards or samples, anti-cortisol antibody and horseradish peroxidase-labeled avidin were subsequently added. Absorbance (optical density) was read using a Multiskan microplate reader at $450 \mathrm{~nm}$, following a substrate 3,3',5,5'-tetramethylbenzidine color reaction. Sample concentrations were calculated using a standard curve.

Western blot analysis. Synovial fibroblasts, seeded in 6-well plates and grown to $80 \%$ confluency, were washed twice with ice-cold PBS and scraped off the wells in TRIzol lysates, containing $1 \%$ protease inhibitors. Cells were collected in $1.5 \mathrm{ml}$ Eppendorf tubes and centrifuged 19,419 at $\mathrm{x} g$ for $10 \mathrm{~min}$ at $4^{\circ} \mathrm{C}$, prior to determination of protein concentration, using a Bradford-based assay (Beyotime institute of Biotechnology, Shanghai, China). Protein samples $(100 \mu \mathrm{g})$ were separated by $30 \%$ SDS-PAGE, and electroblotted on a polyvinylchloride membrane. Following 1-h incubation in blocking buffer [Tris-buffered saline-Tween-20 (TBS-T) with 5\% non-fat dried milk], membranes (Millipore Saint-Quentin-en-Yvelines,
France) were incubated overnight at $4^{\circ} \mathrm{C}$ with $\beta$-actin $(1: 2,000$; cat. no. 4967; Cell Signaling Technology, Inc., Danvers, MA, USA), 11 $\beta$-HSD1 (cat. no. sc-20175; Santa Cruz Biotechnology, Dallas, TX, USA) and mPGES-1 (both 1:500; cat. no. 13035; Cell Signaling Technology, Inc) primary antibodies diluted in TBS-T with $5 \%$ bovine serum albumin. Following three washes with TBS-T, the membrane was incubated for $2 \mathrm{~h}$ at room temperature with anti-rabbit IgG conjugated with horseradish peroxidase (cat. no. sc-2374; Santa Cruz Biotechnology, Inc.) at 1:2,000 dilution in TBS-T containing 5\% non-fat dried milk. Cells were washed three times for $10 \mathrm{~min}$ with TBS-T and protein bands were detected by chemiluminescence, using a Phototope Detection system in accordance with the manufacturer's instructions (Beyotime Institute of Biotechnology, Shanghai, China). The gray values of protein bands were analyzed using Image J software (ver. 1.46; National Institutes of Health, Bethesda, MD, USA). The relative expression of the target protein was calculated according the following formula: Relative expression of target protein $=$ target protein gray value/corresponding internal reference value.

Statistical analysis. Results are expressed as the mean \pm standard deviation. A minimum of three assays were performed. Comparisons were made using analysis of variance analysis, followed by a least significant difference test and subsequent homogeneity of variance test. Correlation analysis between the groups was performed using Pearson correlation analysis. SPSS 21.0 software (IBM SPSS, Armonk, NY, USA) was used for statistical analyses. $\mathrm{P}<0.05$ was considered to indicate a statistically significant difference.

\section{Results}

Evaluation of the isolatedprimarysynovialfibroblasts.Primary synovial fibroblasts, derived from the fibrous membrane of SD rat knees, were used as the model cells for the present study. Cells were isolated using the tissue culture (Fig. 1A) method and were passaged to the third generation (Fig. 1B) and subsequently evaluated by immuohistochemical staining and flow cytometry. Type B synoviocytes, or FLS, are mesenchymal cells that display various characteristics of fibroblasts, including expression of type IV and V collagens, vimentin, and CD90. Cells that were stained brown indicated the presence of vimentin (Fig. 1C), compared with the cells in negative control group (Fig. 1D). Using flow cytometry, while cells marked with homotype-negative phycoerythrin-labeled IgG antibodies showed negative result (Fig. 1E), CD90-positive cells were detected and confirmed the phenotype of type $B$ synovial fibroblasts (Fig. 1F).

\section{$I L-1 \beta$ induces the expression of fibroblast inflammatory} cytokines. Primary synovial fibroblasts derived from the fibrous membrane of SD rat knees were used as model cells to examine the expression levels of inflammatory factors induced by IL-1 $\beta$. Expression levels of the inflammatory cytokines, IL-1 $\beta$ and TNF- $\alpha$ were significantly increased following induction with $10 \mathrm{ng} / \mathrm{ml} \mathrm{IL-1} \beta$ for $24 \mathrm{~h}$, when compared with the control, group A ( $\mathrm{P}<0.05$; Fig. 2), which indicated that IL-1 $\beta$ leads to an inflammatory state in a cell. However, the expression levels of inflammatory cytokines significantly 
A

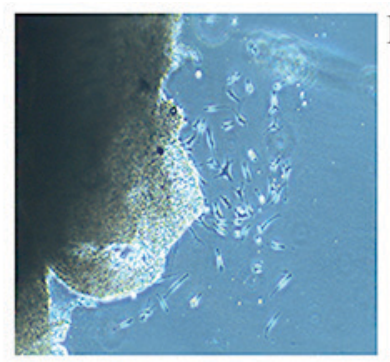

$\mathbf{E}$

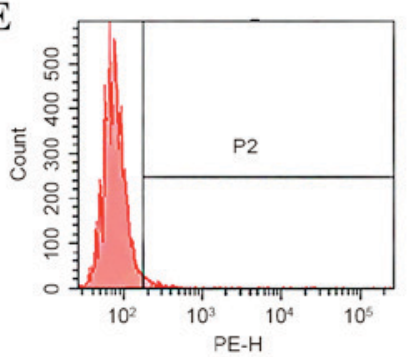

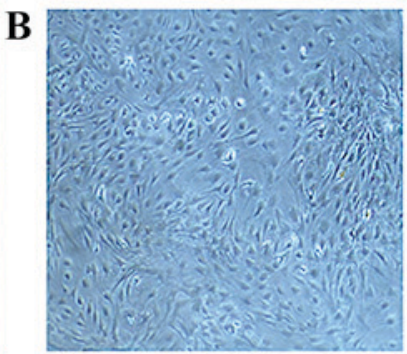
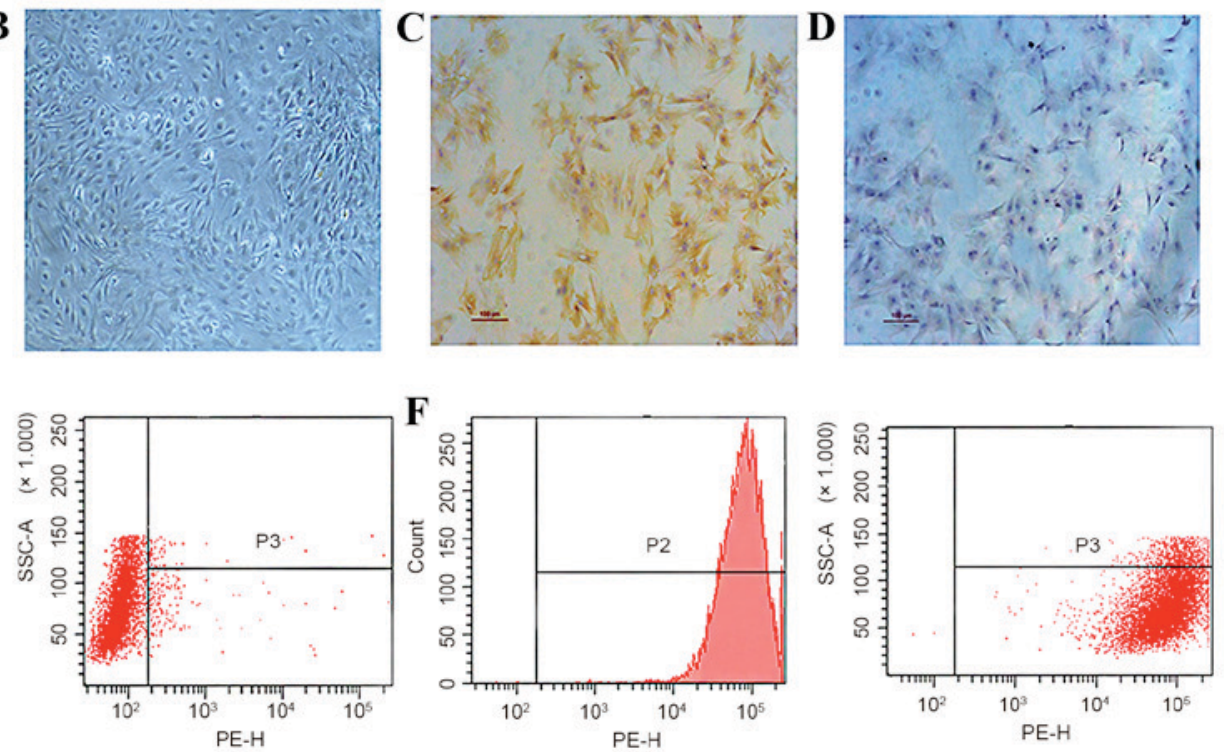

Figure 1. Evaluation of isolated synovial fibroblasts from passage 3 using vimentin staining and CD90 detection by flow cytometry. (A and B) Isolated cells from synovial membranes of Sprague-Dawley rat knees (magnification, x40). (C) Vimentin in the synovial cells was stained brown (magnification, x100; immunocytochemical staining with diaminobenzidine chromogen). (D) PBS was used instead of vimentin staining to act as a negative control (magnification, x100). (E) Cells were marked with homotype-negative phycoerythrin-labeled IgG antibody (negative control). (F) Positive cells marked with CD90 were detected by flow cytometry and indicated that the phenotype conformed to synovial fibroblasts. CD90, cluster of differentiation-90; IgG, immunoglobulin G.
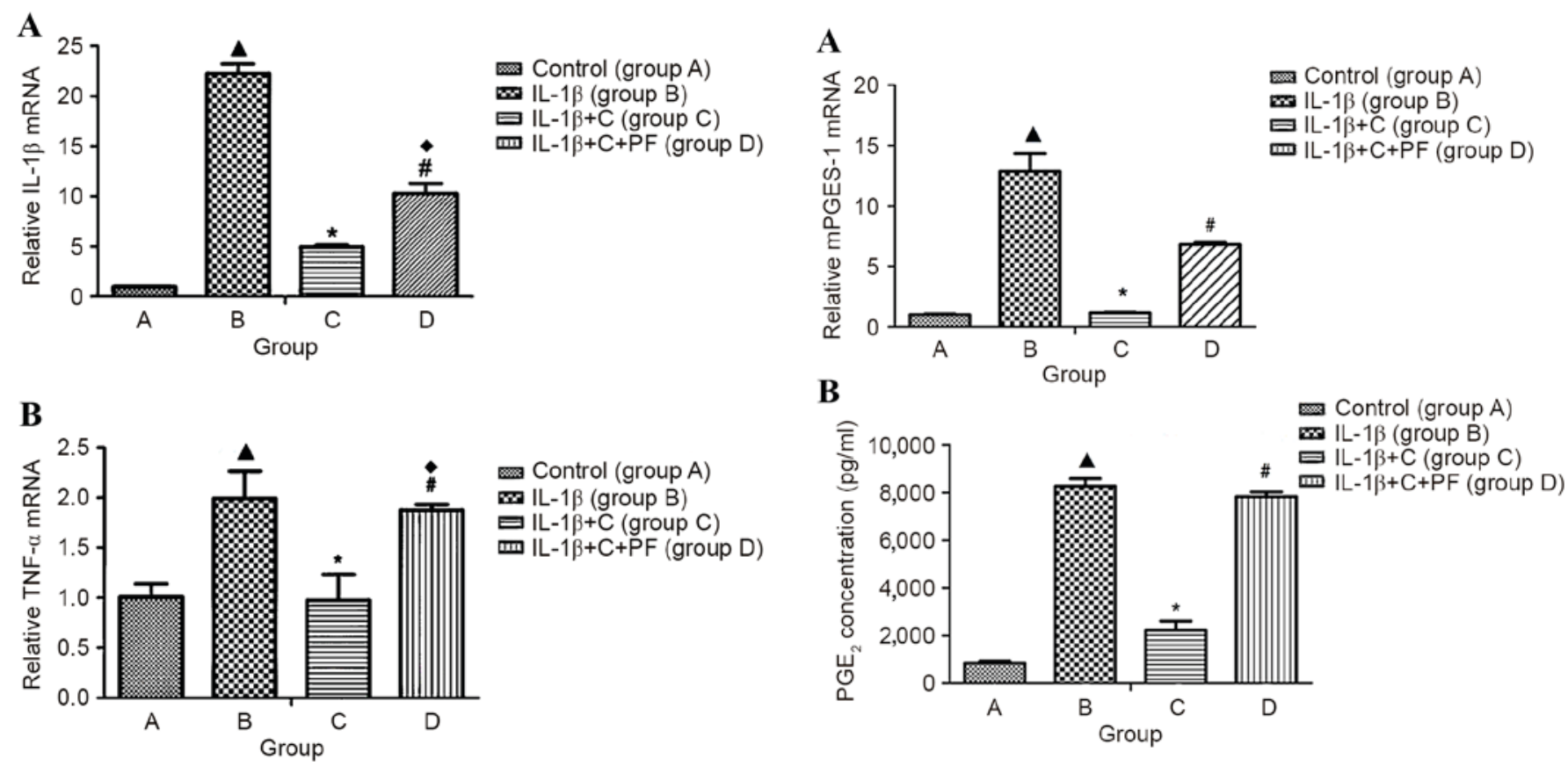

Figure 2. IL-1 $\beta$ inducible inflammatory factor expression in synovial fibroblasts. Synovial fibroblasts were stimulated with $10 \mathrm{ng} / \mathrm{ml} \mathrm{IL-1 \beta}$ for $24 \mathrm{~h}$. Following a further $24 \mathrm{~h}$, cells in group A were treated with Dulbecco's modified Eagle's medium medium without glucocorticoid; group B, with $10 \mathrm{ng} / \mathrm{ml} \mathrm{IL}-1 \beta$; group C, with $10 \mathrm{ng} / \mathrm{ml} \mathrm{IL}-1 \beta$ and $10^{-6} \mathrm{mmol} / 1$ corticosterone; and group D, as group C plus $100 \mathrm{nmol} / 1 \mathrm{PF}$. Expression of (A) IL-1 $\beta$ and (B) TNF- $\alpha$ mRNA increased significantly in the IL-1 $\beta$ - induced synovial fibroblasts. When corticosterone was applied, the expression of inflammatory cytokines significantly decreased. The 11 $\beta$-HSD1 inhibitor, $\mathrm{PF}$, reversed the reduction in expression of inflammatory factors caused by corticosterone. Results are expressed as the mean \pm standard deviation and a minimum of three assays were performed. ${ }^{\wedge} \mathrm{P}<0.05$ vs. control; ${ }^{*} \mathrm{P}<0.05$ vs. group $\mathrm{B} ;{ }^{*} \mathrm{P}<0.05$ vs. group $\mathrm{C} ;{ }^{+} \mathrm{P}<0.05$ vs. group $\mathrm{B}$. IL, interleukin; TNF- $\alpha$, tumor necrosis factor- $\alpha ; 11 \beta$-HSD1, 11 $\beta$-hydroxysteroid dehydrogenase type 1; C, corticosterone; PF, PF915275 [4'-cyano-biphenyl-4-sulfonic acid (6-amino-pyridin-2-yl) -amide].

Figure 3. mPGES-1 mRNA and $\mathrm{PGE}_{2}$ expression in the inflammatory synovial fibroblasts. Total RNA was isolated from synovial fibroblasts layers, and mRNA was quantified using reverse transcription-quantitative polymerase chain reaction. $\mathrm{PGE}_{2}$ was detected by ELISA. (A) mPGES-1 mRNA and (B) $\mathrm{PGE}_{2}$ expression levels were significantly increased in the synoviocytes induced by IL- $1 \beta$ when compared with the control, group A. However, IL-1 $\beta$-induced expression was inhibited significantly by corticosterone, and the inhibitory effect of corticosterone was significantly reversed by the 11ß-HSD1 inhibitor PF. Group A, synovial fibroblasts treated with medium without glucocorticoid (control); group B, synovial fibroblasts treated with $10 \mathrm{ng} / \mathrm{ml} \mathrm{IL}-1 \beta$; group C, synovial fibroblasts treated with $10 \mathrm{ng} / \mathrm{ml} \mathrm{IL}-1 \beta$ and $10^{-6} \mathrm{mmol} / 1$ corticosterone; group D, synovial fibroblasts treated as group C plus $100 \mathrm{nmol} / 1 \mathrm{PF} .{ }^{\wedge} \mathrm{P}<0.05$ vs. control; ${ }^{*} \mathrm{P}<0.05$ vs. group $\mathrm{B}$; ${ }^{\prime \prime} \mathrm{P}<0.05$ vs. group C. C, corticosterone; PF, PF915275 [4'-cyano-biphenyl-4-sulfonic acid (6-amino-pyridin-2-yl)-amide]; mPGES-1, microsomal prostaglandin E synthase-1; $\mathrm{PGE}_{2}$, prostaglandin E2. 


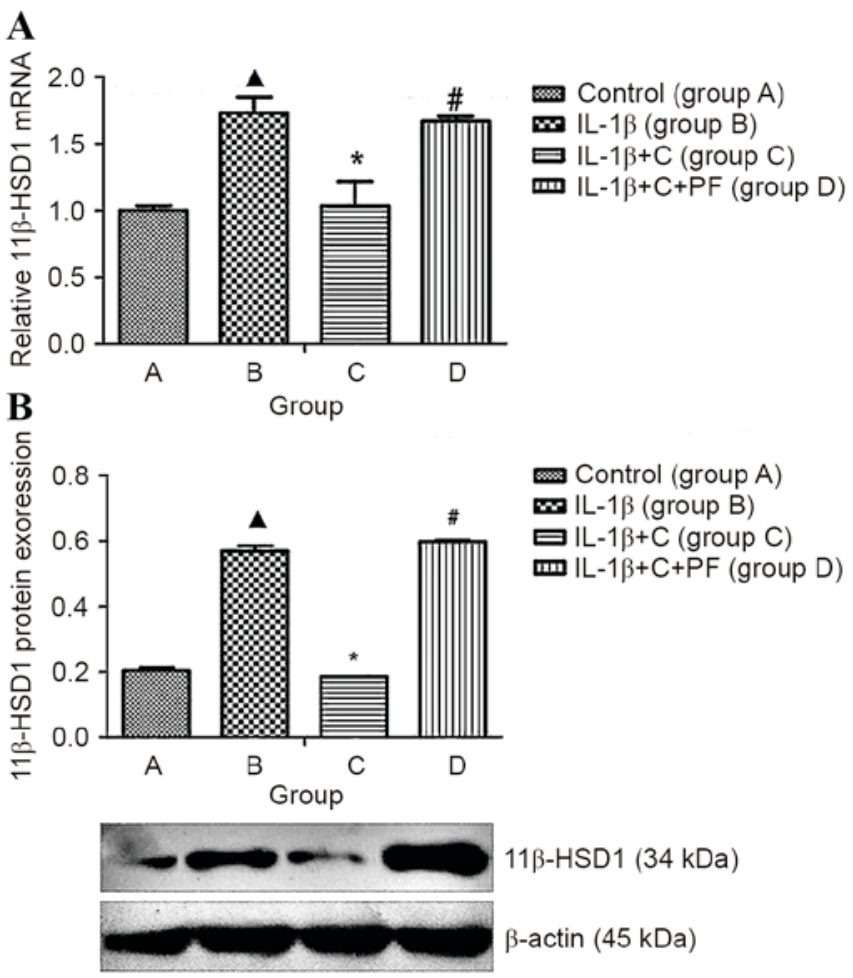

Figure 4. IL-1 $\beta$ induced 11 $\beta$-HSD1 expression and biosynthesis in synovial fibroblasts. 11 $\beta$-HSD1 RNA isolated from synovial fibroblasts layers was quantified using reverse transcription-quantitative polymerase chain reaction, and protein levels were determined by western blotting. 11ß-HSD1 expression was increased at the (A) mRNA and (B) protein levels when compared with the control, group A. When treated with corticosterone, the expression levels were inhibited significantly. Inhibitory effects were reversed by treatment with the 11 $\beta$-HSD1 inhibitor PF. Results are expressed as the mean \pm standard deviation and a minimum of three assays were performed. Group A, synovial fibroblasts treated with medium without glucocorticoid

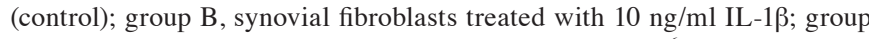
C, synovial fibroblasts treated with $10 \mathrm{ng} / \mathrm{ml} \mathrm{IL}-1 \beta$ and $10^{-6} \mathrm{mmol} / 1$ corticosterone; group D, synovial fibroblasts treated as group C plus $100 \mathrm{nmol} / \mathrm{l} \mathrm{PF}$. ${ }^{\Delta} \mathrm{P}<0.05$ vs. control; ${ }^{*} \mathrm{P}<0.05$ vs. group $\mathrm{B}$; ${ }^{\#} \mathrm{P}<0.05$ vs. group $\mathrm{C}$. $11 \beta$-HSD1, 11 $\beta$-hydroxysteroid dehydrogenase type $1 ; \mathrm{C}$, corticosterone; PF, PF915275 [4'-cyano-biphenyl-4-sulfonic acid (6-amino-pyridin-2-yl) -amide].

decreased compared with those in group B following the administration of corticosterone ( $\mathrm{P}<0.05$; Fig. 2), suggesting an inhibitory effect of corticosterone on IL-1 $\beta$-induced inflammation. However, when cells were treated with PF915275 (group D), an 11 $\beta$-HSD1 inhibitor, the decreased expression levels of inflammatory factors (suppressed by corticosterone) exhibited a reversal effect, with a significant increase $(\mathrm{P}<0.05)$ in the expression levels of IL- $1 \beta$ and TNF- $\alpha$ compared with those in group C (Fig. 2). In comparison with group B, a relatively low expression level of the inflammatory factors IL- $1 \beta$ and TNF- $\alpha$ was observed in group $\mathrm{D}(\mathrm{P}<0.05)$.

$\mathrm{PGE}_{2}$ is a key factor involved in the development and perpetuation of inflammation in disease, such as with rheumatoid arthritis. In this disease, local inflammation of synovial tissue is characterized, in part, by increased local levels of PG, predominantly $\mathrm{PGE}_{2}(5)$. Inducible mPGES-1 has an essential role in the localized increase of $\mathrm{PGE}_{2}$ during inflammatory arthritis. Expression notably increased when cells were induced by pro-inflammatory cytokines (IL-1 $\beta$ and TNF- $\alpha$ ) in vitro (6). In the present study, mPGES-1

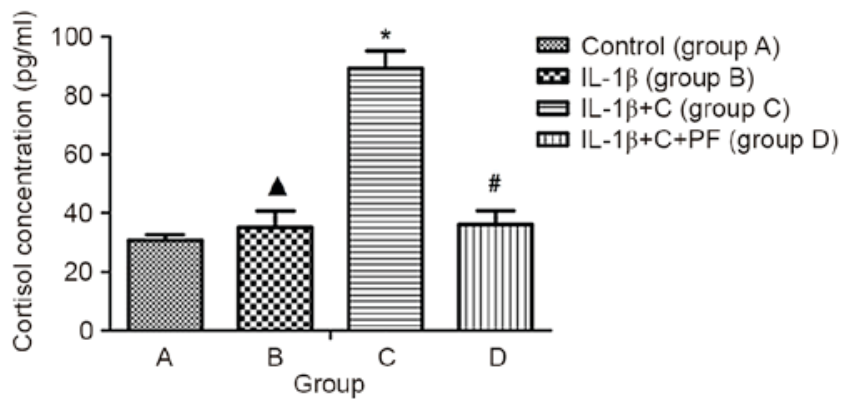

Figure 5. ELISA of cortisol concentration in the medium. Cortisol concentration was assayed in culture supernatants using an ELISA kit to indicate the conversion rate of cortisone. The absorbance (OD) was read using a micro Multiskan plate reader at $450 \mathrm{~nm}$ after the substrate TMB color reaction. IL-1 $\beta$ did not affect the cortisol concentration in the medium. Cortisol concentration increased significantly following the addition of corticosterone; however, this was reversed when PF was included. Results are expressed as the mean \pm standard deviation and a minimum of three assays were performed. ${ }^{\wedge} \mathrm{P}>0.05$ vs. control; ${ }^{*} \mathrm{P}<0.05$, vs. control; ${ }^{*} \mathrm{P}<0.05$ vs. group C. Group A, synovial fibroblasts treated with medium without glucocorticoid

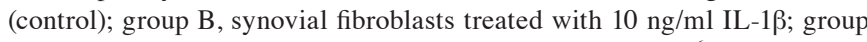
$\mathrm{C}$, synovial fibroblasts treated with $10 \mathrm{ng} / \mathrm{ml} \mathrm{IL}-1 \beta$ and $10^{-6} \mathrm{mmol} / 1$ corticosterone; group D, synovial fibroblasts treated as group C plus $100 \mathrm{nmol} / 1$ PF. OD, optical density; TMB, 3,3',5,5'-tetramethylbenzidine; $11 \beta$-HSD1, $11 \beta$-hydroxysteroid dehydrogenase type 1 ; C, corticosterone; PF, PF915275 [4'-cyano-biphenyl-4-sulfonic acid (6-amino-pyridin-2-yl) -amide].

mRNA expression and $\mathrm{PGE}_{2}$ production of synovial fibroblasts were significantly increased following treatment with $10 \mathrm{ng} / \mathrm{ml} \mathrm{IL}-1 \beta$ for $24 \mathrm{~h}$, when compared with the control, group A (P<0.05; Fig. 3).

$I L-1 \beta$ induces $11 \beta-H S D 1$ expression in fibroblasts by suppressing corticosterone activation. $11 \beta-\mathrm{HSD} 1$ is capable of converting inactive glucocorticoids (cortisone and prednisone) into the active counterparts, cortisol and prednisolone. Synovial fibroblasts and osteoblasts generate active glucocorticoids through the expression of $11 \beta$-HSD1 (7). Such activity increases, in vitro, in response to pro-inflammatory cytokines or glucocorticoids. The present study indicated that IL- $1 \beta$ significantly increased 11 $\beta$-HSD1 expression levels in synoviocytes $(\mathrm{P}<0.05)$, whereas these expression levels markedly decreased when corticosterone was added to the media (Fig. 4), which may be due to an increase in the production of active cortisol (Fig. 5) and the inhibition of the synoviocyte inflammation. When the activity of $11 \beta$-HSD1 was inhibited by PF915275, the $11 \beta$-HSD1 mRNA and protein expression levels that had previously been suppressed by corticosterone were reversed, and the expression levels were higher than those of cells stimulated with IL-1 $\beta$ ( $\mathrm{P}<0.05$; Fig. 4).

Corticosterone suppresses synoviocyte $P G E_{2}$ production by promoting the activity of $11 \beta$-HSD1. Synovial fibroblasts expressed high levels of mPGES-1 mRNA when treated with IL-1 $\beta$, and $\mathrm{PGE}_{2}$ concentration was higher in the media when compared with the control, group A, as detected by ELISA $(\mathrm{P}<0.05$; Fig. 3). Corticosterone appeared to counteract the effects of IL-1 $\beta$, as indicated by the reduction in expression of mPGES-1 mRNA and $\mathrm{PGE}_{2}(\mathrm{P}<0.05$; Fig. 3). This inhibitory effect may result from a low level of active corticosterone that inhibited 11ß-HSD1 expression; thus corticosterone may be 
A

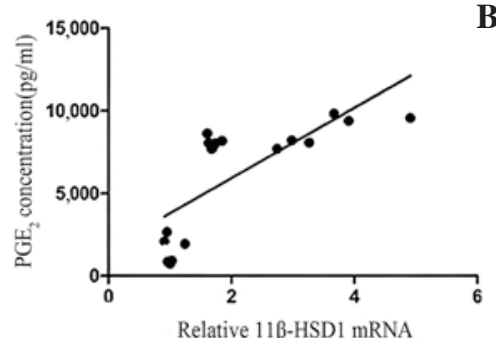

B

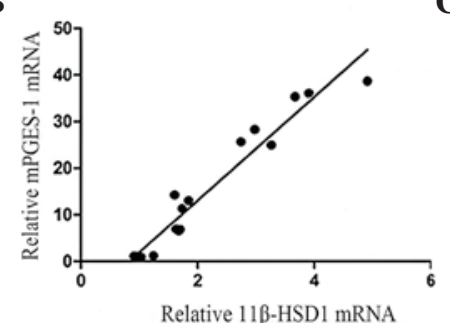

C

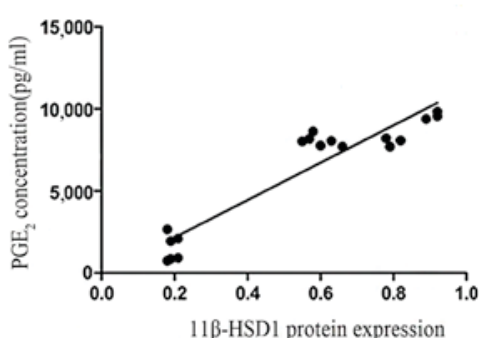

Figure 6. Correlation analysis between 11 $\beta$-HSD1 and mPGES-1 expression, and $\mathrm{PGE}_{2}$ production in inflammatory synoviocytes. Correlation of (A) $11 \beta$-HSD1

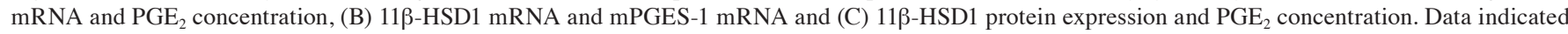
that there were significantly positive correlations between (A) $\mathrm{PGE}_{2}$ concentration and $11 \beta$-HSD1 mRNA expression $(\mathrm{r}=0.74, \mathrm{P}<0.01)$, (B) mPGES-1 mRNA expression and relative 11 $\beta$-HSD1 mRNA expression $(r=0.97, \mathrm{P}<0.01)$ as well as $(\mathrm{C}) \mathrm{PGE}_{2}$ concentration and 11 $\beta$-HSD1 protein expression $(\mathrm{r}=0.94, \mathrm{P}<0.01)$. 11 $\beta$-HSD1, 11 $\beta$-hydroxysteroid dehydrogenase type 1; mPGES-1, microsomal prostaglandin E synthase-1; PGE $_{2}$, prostaglandin E2.

effectively converted by synoviocytes (Fig. 5). In the present study, PF915275 was used to suppress the conversion activity of 11ß-HSD1. Suppression by PF915275 caused a significant increase in the levels of mPGES-1 mRNA (Fig. 3A) expression in synoviocytes and the concentration of $\mathrm{PGE}_{2}$ (Fig. 3B) in the media, when compared with the control and corticosterone groups (groups $\mathrm{A}$ and $\mathrm{C}$, respectively; $\mathrm{P}<0.05$ ). mPGES-1 mRNA and $\mathrm{PGE}_{2}$ were not inhibited when the conversion activity of enzyme 11 $\beta$-HSD1 was blocked ( $\mathrm{P}>0.05$, compared with the control group; Fig. 3). These results suggest that $\mathrm{PGE}_{2}$ production by the synoviocytes may be suppressed by activating the 11 $\beta-H S D 1$ pathway.

$11 \beta-H S D 1$ expression positively correlates with $P G E_{2}$ concentration in inflammatory synoviocytes. Synovial fibroblasts treated with IL-1 $\beta$ exhibited significantly increased mRNA levels of 11 $\beta$-HSD1 (Fig. 4A) and mPGES-1 (Fig. 3A) when compared with the normal synoviocytes $(\mathrm{P}<0.05)$. $11 \beta$-HSD1 and $\mathrm{PGE}_{2}$ proteins were increasingly expressed in the inflammatory synoviocytes; however, the association between $11 \beta$-HSD1 and $\mathrm{PGE}_{2}$ was unclear. 11 $\beta$-HSD1 mRNA and protein expression levels in the inflammatory synoviocytes were found to be positively correlated with $\mathrm{PGE}_{2}$ concentration $(\mathrm{r}=0.74, \mathrm{P}<0.01$ and $\mathrm{r}=0.94, \mathrm{P}<0.01$; Fig. 6). The positive correlation between $11 \beta-H S D 1$ and mPGES-1 mRNA expression levels was significant $(\mathrm{r}=0.97$, $\mathrm{P}<0.01$; Fig. 6).

\section{Discussion}

Synovial fibroblasts are important functional compartments that contribute to the production of lubricious synovial fluid and diffusion of the nutrients (16). Synovial fibroblasts are mesenchymal cells that display multiple characteristics of fibroblasts, including expression of type IV and V collagens, vimentin, and CD90 (Thy-1) (16). CD90, which is evolutionarily conserved and developmentally regulated, often has marked effects on cell phenotype and is a specific surface marker expressed by synovial fibroblasts $(17,18)$. In isolated situations, the expression or lack of expression of CD90 has been used to separate fibroblast subsets (19). Vimentin is the specific protein marker expressed by cells derived from the mesoderm and is used for cell isolation (20). In the present study, purified cells derived from synovial membranes in SD rat knees were stained vimentin-positive, due to the expression of the surface marker CD90. These results indicated that the cells were confirmed to be synovial fibroblasts, which was consistent with the literature (21). However, the proliferative activity of synovial fibroblasts declined significantly in the seven generations of culturing. Therefore, FLS at passage three, with high purity and suitable activity were used in the present study.

Synovial inflammation is an important contributor to OA pathogenesis $(2,22,23)$. Synovitis has been demonstrated to correlate with OA symptom severity, and hormonal factors, such as cytokines and chemokines, are important for crosstalk in joint tissues $(23,24)$. These mediators have a critical role in the development of inflammation and induce catabolic changes in joint tissues $(2,23,25,26)$. Studies have demonstrated that FLS produce inflammatory cytokines (such as TNF- $\alpha$ and IL-1 $\beta$ ) and chondrolytic mediators, including matrix metalloproteinases (27). IL-1 $\beta$ and TNF- $\alpha$, which are the two most extensively studied factors, have been implicated in the pathogenesis of OA $(22,23)$. In the present study, when stimulated by IL-1 $\beta$, FLS expressed increased levels of IL- $1 \beta$, TNF- $\alpha$ and mPGEs- 1 and produced high concentrations of $\mathrm{PGE}_{2}$ in the medium. The present data indicated that the inflammatory state in the FLS induced by IL-1 $\beta$ was suitable for this study.

The tissue availability of active glucocorticoids is dependent on their rate of synthesis from cholesterol, downstream metabolism, excretion and interconversion (28). The latter is mediated by $11 \beta-H S D$ s. $11 \beta-H S D$ is a glucocorticoid pre-receptor regulating enzyme that regulates the local concentration of glucocorticoid through its oxidation effect (9). Non-oxidized corticosteroids, such as cortisone and 11-dehydrogenation of corticosterone, cannot combine with the glucocorticoid receptor and thus have an effective role in biological function. The only way to promote activation is by $11 \beta$-HSD1 transformation (29). A prior study considered that the sustained inflammatory state of arthritis is due to the partial abnormal hormone metabolism in tissues (30). Synovitis is an important cause of chronic, persistent OA. In animal models of arthritis, 11 $\beta$-HSD1 gene knockout increases the risk of original joint inflammation (31), suggesting a positive effect of 
$11 \beta$-HSD1 on controlling the severity of arthritis. However, the underlying mechanism remains unknown. 11ß-HSD1-related genes and proteins of IL-1 $\beta$ and TNF- $\alpha$ are upregulated in various stromal cells (32). In this study, the cortisol concentration in the medium was detected by ELISA to determine the conversion activity of $11 \beta$-HSD1; $11 \beta$-HSD1 was highly expressed when stimulated by IL-1 $\beta$, whereas cortisol concentration remained at a low level. As the substrate corticosterone was added, the concentration increased significantly. By contrast, 11 $\beta$-HSD1 levels decreased, indicating 11 $\beta$-HSD1 was blocked by PF915275. These results suggested that FLS had an active transformation ability in cortisol activation; and the cortisol/cortisone ratio in the medium and 11 $\beta$-HSD1 expression were regulated under a feedback mechanism.

The present study also demonstrated that normal synovial fibroblasts, induced by IL-1 $\beta$, highly expressed $11 \beta$-HSD1 gene and protein. Li et al (33) reported that IL-1 $\beta$ and other inflammatory mediators are able to jointly upregulate $11 \beta$-HSD1 mRNA in amnion; however, it has not yet been reported in the literature whether a similar regulating mechanism in synovial fibroblasts exists. In the present study, interactions between IL-1 $\beta$ and glucocorticoid were identified. When synovial fibroblasts were interfered with IL-1 $\beta$ and corticosterone, the expression of $11 \beta$-HSD1 decreased, which suggested that functional normal synovial cells can be activated by the enzymatic conversion of corticosterone and produce corticosteroids (cortisol) locally to exert anti-inflammatory effects. Therefore, high expression of 11 $\beta$-HSD1 may attenuate the inflammatory state. By contrast, when enzyme activity and/or glucocorticoid receptor was inhibited, the concentration of local activated cortical hormone decreased and the probability of binding with its receptor also decreased, thus 11 $\beta$-HSD1 failed to suppress the local inflammatory state effectively. However, when the involved inflammatory factors increased to high levels, expression of $11 \beta$-HSD1 was initiated and increased in response to inflammation. These data suggest that hormone levels regulated by $11 \beta$-HSD 1 pre-receptor have a critical role in controlling synovitis, and such regulation may have a feedback mechanism.

In the pathological process of OA, the secretion of inflammatory factors, such as $\mathrm{PGE}_{2}$ have an important role in the development of synovitis, cartilage matrix disintegration and bone destruction (8). $\mathrm{PGE}_{2}$ dilates blood vessels and induces alterations in second messenger level via autocrine/paracrine signaling (34). Jia et al (35) identified that $\mathrm{PGE}_{2}$ receptors present in arthritic tissue may combine with $\mathrm{PGE}_{2}$, and subsequently induce cartilage degradation, glycosaminoglycan loss and collagen type II degradation in OA animal models. However, these pathological changes can be alleviated in $\mathrm{PGE}_{2}$ receptor knockout mice. Sun and Myatt (11) reported that IL-1 $\beta$ was able to significantly improve $11 \beta$-HSD1 mRNA expression and activity. With prior induction of $11 \beta$-HSD1 expression by dexamethasone, cortisone induced more $\mathrm{PGE}_{2}$ production in the amnion fibroblast. This study suggests that glucocorticoids are able to positively induce $11 \beta$-HSD1 expression in amnion fibroblasts and this effect was further strengthened by pro-inflammatory cytokines. However, in synovial B cells, whether glucocorticoids affect 11 $\beta$-HSD1 expression and $\mathrm{PGE}_{2}$ biosynthesis remains unclear. In the present study, IL-1 $\beta$ significantly induced mPGEs- 1 and PGE $_{2}$ expression in synoviocytes, and corticosterone effectively inhibited this effect. However, when the transformation activity of 11 $\beta$-HSD1 was blocked by PF915275, the activated corticosterone (cortisol) production decreased significantly and the inhibitive effect of $\mathrm{PGE}_{2}$ was reversed. This indicated that the pre-receptor activity is able to effectively regulate the expression and biological effect of $\mathrm{PGE}_{2}$ in FLS.

Both 11 $\beta-H S D 1$ and mPGES are present in microsomes and co-exist in the complex pathogenesis of $\mathrm{OA}$. $\mathrm{PGE}_{2}$ is an important inflammatory factor in the human body. 11 $\beta$-HSD1 has an important role in regulating anti-inflammatory substance levels, and thus activating glucocorticoid hormone mPGEs-1, which is an inducible key limited enzyme, to control $\mathrm{PGE}_{2}$ production in inflammation process (25). In the present study, a preliminary analysis was constructed to elucidate the association between the expression and production of mPGEs-1, $\mathrm{PGE}_{2}$, and 11 $\beta$-HSD1 in synoviocytes under an inflammatory state. The results revealed significant positive linear correlations between them, both at the gene and protein expression levels. To date, no reports exist on whether $\mathrm{PGE}_{2}$ and $11 \beta$-HSD1 promote each other in synovial B cells under osteoarthritis conditions. Subsequently, the underlying mechanisms of interactions between $11 \beta$-HSD1, mPGEs-1 and PGE ${ }_{2}$ require further investigation.

\section{Acknowledgements}

The present study was supported by the Science and Technology Planning Project of Guangdong Province, People's Republic of China (grant no. 2011B031800172) and the Foundation for the PhD Start-up Fund of the Affiliated Hospital of Guangdong Medical College, People's Republic of China (grant no. BK201209).

\section{References}

1. Felson DT, Niu J, Neogi T, Goggins J, Nevitt MC, Roemer F, Torner J, Lewis CE and Guermazi A; MOST Investigators Groups: Synovitis and the risk of knee osteoarthritis: The MOST Study. Osteoarthritis Cartilage 24: 458-464, 2016.

2. Scanzello CR and Goldring SR: The role of synovitis in osteoarthritis pathogenesis. Bone 51: 249-257, 2012.

3. Pessler F, Dai L, Diaz-Torne C, Gomez-Vaquero C, Paessler ME, Zheng DH, Einhorn E, Range U, Scanzello C and Schumacher HR: The synovitis of 'non-inflammatory' orthopaedic arthropathies: A quantitative histological and immunohistochemical analysis. Ann Rheum Dis 67: 1184-1187, 2008.

4. Wei Y and Bai L: Recent advances in the understanding of molecular mechanisms of cartilage degeneration, synovitis and subchondral bone changes in osteoarthritis. Connect Tissue Res 57: 245-261, 2016.

5. Bhattaram P and Chandrasekharan U: The joint synovium: A critical determinant of articular cartilage fate in inflammatory joint diseases. Semin Cell Dev Biol: May 19, 2016 (Epub ahead of print).

6. Bondeson J, Blom AB, Wainwright $\mathrm{S}$, Wainwright $\mathrm{S}$, Hughes $\mathrm{C}$, Caterson B and van den Berg WB: The role of synovial macrophages and macrophage-produced mediators in driving inflammatory and destructive responses in osteoarthritis. Arthritis Rheum 62: 647-657, 2010.

7. Blasioli DJ, Matthews GL and Kaplan DL: The degradation of chondrogenic pellets using cocultures of synovial fibroblasts and U937 cells. Biomaterials 35: 1185-1191, 2014.

8. Roshak A, Mochan E and Marshall LA: Suppression of human synovial fibroblast $85 \mathrm{KDa}$ phospholipase A2 by antisense reduces interleukin-1 beta induced prostaglandin E2. J Rheumatol 23: 420-427, 1996. 
9. Hardy R, Rabbitt EH, Filer A, Emery P, Hewison M, Stewart PM, Gittoes NJ, Buckley CD, Raza K and Cooper MS: Local and systemic glucocorticoid metabolism in inflammatory arthritis. Ann Rheum Dis 67: 1204-1210, 2008.

10. Hardy RS, Filer A, Cooper MS, Parsonage G, Raza K, Hardie DL, Rabbitt EH, Stewart PM, Buckley CD and Hewison M: Differential expression, function and response to inflammatory stimuli of 11beta-hydroxysteroid dehydrogenase type 1 in human fibroblasts: A mechanism for tissue-specific regulation of inflammation. Arthritis Res Ther 8: R108, 2006.

11. Sun K and Myatt L: Enhancement of glucocorticoid-induced 11beta-hydroxysteroid dehydrogenase type 1 expression by proinflammatory cytokines in cultured human amnion fibroblasts. Endocrinology 144: 5568-5577, 2003.

12. Tomlinson JW, Moore J, Cooper MS, Bujalska I, Shahmanesh M, Burt C, Strain A, Hewison M and Stewart PM: Regulation of expression of 11beta-Hydroxysteroid dehydrogenase type 1 in adipose tissue: Tissue-specific induction by cytokines. Endocrinology 142: 1982-1989, 2001.

13. Newton R, Kuitert LM, Slater DM, Adcock IM and Barnes PJ: Cytokine induction of cytosolic phospholipase A2 and cyclooxygenase-2 mRNA is suppressed by glucocorticoids in human epithelial cells. Life Sci 60: 67-78, 1997.

14. Hoeck WG, Ramesha CS, Chang DJ, Fan N and Heller RA: Cytoplasmic phospholipase A2 activity and gene expression are stimulated by tumor necrosis factor: Dexamethasone blocks the induced synthesis. Proc Natl Acad Sci USA 90: 4475-4479, 1993

15. Livak KJ and Schmittgen TD: Analysis of relative gene expression data using real-time quantitative PCR and the 2(-Delta Delta C(T)) Method. Methods 25: 402-408, 2001.

16. Bartok B and Firestein GS: Fibroblast-like synoviocytes: Key effector cells in rheumatoid arthritis. Immunol Rev 233: 233-255, 2010.

17. Zimmermann T, Kunisch E, Pfeiffer R, Hirth A, Stahl HD, Sack U, Laube A, Liesaus E, Roth A, Palombo-Kinne E, et al: Isolation and characterization of rheumatoid arthritis synovial fibroblasts from primary culture-primary culture cells markedly differ from fourth-passage cells. Arthritis Res 3: 72-76, 2001.

18. Bradley JE, Ramirez G and Hagood JS: Roles and regulation of Thy-1, a context-dependent modulator of cell phenotype. Biofactors 35: 258-265, 2009.

19. Sorrell JM and Caplan AI: Fibroblasts-a diverse population at the center of it all. Int Rev Cell Mol Biol 276: 161-214, 2009.

20. Ota F, Maeshima A, Yamashita S, Ikeuchi H, Kaneko Y, Kuroiwa T, Hiromura K, Ueki K, Kojima I and Nojima Y: Activin A induces cell proliferation of fibroblast-like synoviocytes in rheumatoid arthritis. Arthritis Rheum 48: 2442-2449, 2003.
21. Lefèvre S, Knedla A, Tennie C, Kampmann A, Wunrau C, Dinser R, Korb A, Schnäker EM, Tarner IH, Robbins PD, et al: Synovial fibroblasts spread rheumatoid arthritis to unaffected joints. Nat Med 15: 1414-1420, 2009.

22. Sellam J and Berenbaum F: The role of synovitis in pathophysiology and clinical symptoms of osteoarthritis. Nat Rev Rheumatol 6: 625-635, 2010.

23. Goldring MB and Otero M: Inflammation in osteoarthritis. Curr Opin Rheumatol 23: 471-478, 2011.

24. Goldring MB and Marcu KB: Cartilage homeostasis in health and rheumatic diseases. Arthritis Res Ther 11: 224, 2009.

25. Goldring MB and Goldring SR: Osteoarthritis. J Cell Physiol 213 : 626-634, 2007

26. Lotz M and Loeser RF: Effects of aging on articular cartilage homeostasis. Bone 51: 241- 248, 2012.

27. Sokolove J and Lepus CM: Role of inflammation in the pathogenesis of osteoarthritis: latest findings and interpretations. Ther Adv Musculoskelet Dis 5: 77-94, 2013.

28. Schmidt M and Straub RH: $11 \beta$-hydroxysteroid dehydrogenase enzymes modulate effects of glucocorticoids in rheumatoid arthritis synovial cells. Neuroimmunomodulation 22: 40-45, 2015.

29. Cooper MS and Stewart PM: 11Beta-hydroxysteroid dehydrogenase type 1 and its role in the hypothalamus-pituitary-adrenal axis, metabolic syndrome and inflammation. J Clin Endocrinol Metab 94: 4645-4654, 2009.

30. Bailey E, Greaves MS, Murphy D and West HF: Corticosteroid metabolism and rheumatoid arthritis. Ann Rheum Dis 25: 516-524, 1966.

31. Hardy RS, Seibel MJ and Cooper MS: Targeting 11 $\beta$-hydroxysteroid dehydrogenases: A novel approach to manipulating local glucocorticoid levels with implications for rheumatic disease. Curr Opin Pharmacol 13: 440-444, 2013.

32. Tomlinson JW, Walker EA, Bujalska IJ, Draper N, Lavery GG, Cooper MS, Hewison M and Stewart PM: 11 $\beta$-hydroxysteroid dehydrogenase type 1: A tissue-specific regulator of glucocorticoid response. Endocr Rev 25: 831-866, 2004.

33. Li W, Gao L, Wang Y, Duan T, Myatt L and Sun K: Enhancement of cortisol-induced 11beta-hydroxysteroid dehydrogenase type 1 expression by interleukin lbeta in cultured human chorionic trophoblast cells. Endocrinology 147: 2490-2495, 2006.

34. Lemieux LI, Rahal SS and Kennedy CR: PGE2 reduces arachidonic acid release in murine podocytes: Evidence for an autocrine feedback loop. Am J Physiol Cell Physiol 284: C302-C309, 2003.

35. Jia XY, Chang Y, Sun XJ, Dai X and Wei W: The role of prostaglandin E2 receptor signaling of dendritic cells in rheumatoid arthritis. Int Immunopharmacol 23: 163-169, 2014. 